\title{
Chapter 9 \\ The Causal Structure of Emotions \\ in Aristotle: Hylomorphism, Causal \\ Interaction between Mind and Body, \\ and Intentionality
}

\author{
Gabriela Rossi
}

\begin{abstract}
Recently, a strong hylomorphic reading of Aristotelian emotions has been put forward, one that allegedly eliminates the problem of causal interaction between soul and body. Taking the presentation of emotions in $d e A n$. I 1 as a starting point and basic thread, but relying also on the discussion of $R h$. II, I will argue that this reading only takes into account two of the four causes of emotions, and that, if all four of them are included into the picture, then a causal interaction of mind and body remains within Aristotelian emotions, independent of how strongly their hylomorphism is understood. Beyond the discussion with this recent reading, the analysis proposed of the fourfold causal structure of emotions is also intended as a hermeneutical starting point for a comprehensive analysis of particular emotions in Aristotle. Through the different causes Aristotle seems to account for many aspects of the complex phenomenon of emotion, including its physiological causes, its mental causes, and its intentional object.
\end{abstract}

\subsection{Introduction}

In Aristotle's writings, emotions are discussed within diverse epistemological frameworks, from ethics to philosophy of nature, including also -and most notablyrhetoric. However, Aristotle seems to rely each time on the assumption that we

\footnotetext{
A first version of this paper was read at the Colloquium 'Soul and Mind in Greek Thought. Psychological Issues in Plato and Aristotle' in Santiago de Chile. I warmly thank all the participants of the conference for their comments and suggestions, and especially Marcelo Boeri and Javier Echeñique: both made observations that saved me from oversimplifying some important points. All the remaining flaws are on my account. The final version of this article was produced while the author held a FONDECYT Grant 1170125.

G. Rossi $(\bowtie)$

Universidad Adolfo Ibáñez, Santiago, Chile

e-mail: gabriela.rossi@uai.cl
} 
already share some idea of what an emotion is: a general definition of the emotion and a unified theory of emotions, which would serve as a keystone for every particular treatment of the problem, is conspicuously absent from the Aristotelian corpus. ${ }^{1}$ Some attempts have been made to reconstruct such a theory, but they are allegedly partial, among other causes, because the set of psychophysical states of intentional nature that Aristotle calls 'emotions' is somewhat heterogeneous: some of them are defined as desires, some are not, some have clear ends, which others seem to have not, some involve a feeling of pleasure and/or pain, while in others this is not evident, some entail a belief or judgment while others appear to be based on imagination. It appears that different aspects of emotions are stressed by Aristotle in different texts (and sometimes even within one text) according to the aim that guides each treatment, and it often happens that some aspects that seem crucial to the emotion as presented in one context are (or seem to be) altogether absent in other places. ${ }^{2}$ Hence, the first problem to undertake such a task as a study of Aristotle's conception of emotions is to determine where to start, i.e. which of all the treatments of emotions to take as a basis for an approach to this issue.

From all the Aristotelian treatments of emotions, the most extensive and the most modulated is the one of $R h$. II $1-11$. It is probably for this reason that this text is usually taken as the primary source for the study of Aristotelian emotions. In it, Aristotle offers characterizations of at least fifteen different emotions. However, we should not lose sight of the fact that this detailed discussion answers to specific purposes which are, first, to provide the orator with some strategies to present herself as well disposed towards the audience, ${ }^{3}$ and, second, to identify potentially useful discursive strategies for the orator in order to arouse (or dissolve) a certain emotion in her audience, with the final end of disposing their judgment towards the decision she wants to. Since the main point of the orator is to induce these emotional states in the audience through speech, ${ }^{4}$ this discussion of emotions is especially rich in indications about the sort of beliefs and representations that a person has when he or she feels a certain emotion, so that the orator can eventually induce them. This treatment is of extraordinary interest and has been extensively celebrated within the literature on emotions, even out of Aristotelian scholarship, among other things, because it is taken as a robust development of a cognitivist theory of emotions. ${ }^{5}$

${ }^{1}$ Cf. for instance Fortenbaugh 2002, p. 114; Cooper 1996, pp. 238-239; Striker 1996, p. 287; Rapp 2008, p. 47.

${ }^{2}$ Cf. Leighton 1996, p. 230.

${ }^{3}$ Cooper 1996, pp. 239-240; Frede 1996, p. 265; cf. Arist. Rh. II 1, 1378a6-8 with 1378a18-19.

${ }^{4}$ Aristotle makes clear then that the arousal of emotions he will discuss is the one produced by the

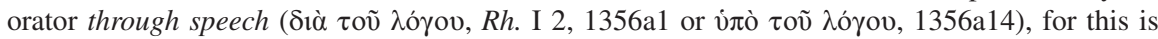
precisely what distinguishes a technical from a non-technical rhetorical move (1355b35-39).

${ }^{5} \mathrm{R}$. Solomon, one of the prominent contemporary theorists on emotions, claims that in $R h$. Aristotle 'developed a strikingly modern theory of emotion that stands up to most contemporary criticism' which he associates with modern cognitivist theories of emotions (Solomon 2003, p. 1; cf. also Goldie 2000, pp. 23-28, for a modern appraisal of Aristotle's discussion of emotions in Rh. II). Solomon himself, being a cognitivist, finds an antecedent of his own position in the Aristotelian conception of emotions of $R h$. Modern so-called cognitivist theories of emotion tend to ascribe a 
While in $R h$. II 1-11 the causal connection between beliefs or imagination and emotion is at the center of stage, in $R h$. I 10-11 emotions are instead discussed as causes of actions, so here the privileged aspect of the emotion is its relation to desire (hence to pleasure) ${ }^{6}$ which is only mentioned in the definition of anger in the discussion of $R h$. II. This perspective coincides in part with $M A 8$ where Aristotle also mentions emotions (together with desire) as a cause of action. ${ }^{7}$ This shift of focus is easily explained: within the context of forensic oratory, the mention of emotions as irrational causes of action in $R h$. I 10 is aimed at providing the orator with potential explanations of a defendant's questionable actions (the ones that brought him or her to court, probably).

Neither of these rhetorical treatments of emotions has scientific or theoretical aspirations. They are destined to the orator's practical purposes. Of course, if they are to be of actual use, they must work with a concept of emotion which corresponds to how they really are; but this concept is never fully explained, even less defined in scientific terms. There is not in these chapters a proper theory of emotions. Something similar happens with several definitions or particular emotions scattered through the Topics, which are of informative value, but cannot be taken as the expression of a full-fledged theory.

From the theoretical point of view, in fact, the most relevant discussion of the phenomenon of emotions is found in de An. I 1. Nevertheless, this is not a theoretical study of emotions in their own right. The goal of Aristotle's discussion here is rather to elucidate the ontological structure of this psychophysical phenomenon, as a paradigmatic case of all (or most of) the affections of soul. Once again, no comprehensive definition or theory of emotions is provided, and the extension of the treatment is this time rather meager. However, this is the most holistic (even if not the most detailed and modulated) of Aristotle's treatments of emotions.

For this reason, I have decided to take the presentation of emotions in de An. I 1 as the basic thread of my contribution. From this text I do not intend to provide a

prominent role to beliefs in emotions; to this extent, they stand against Jamesian theories, that understand the emotion as the perception of a physiological disturbance, this physiological factor having causal and essential priority in the emotion. There is also, however, some debate among Aristotelian scholars about the cognitive nature of the emotions in Aristotle, but I am afraid that in this debate the term 'cognitivist' is used in a slightly different way than in the above mentioned debates, namely it refers to the view that an intellectual, intelligent or rational element is essential to the Aristotelian emotions. This view which sometimes is also called 'doxastic reading' is not necessarily opposed to some form of Jamesianism but to the tenet that the emotions are essentially irrational for Aristotle. For a defense of a strong cognitivist (or doxastic) reading of Aristotelian emotions see especially Fortenbaugh 2002; a different view is held by Cooper 1996, based mostly on the treatment of $R h$. I 10, and more recently J. Moss 2012 argues extensively for the reading that emotions are not functions of the intellect but are essentially non-rational. Outside Aristotelian scholarship, a robust position against the over-intellectualization of emotions in the contemporary debate is maintained by Goldie 2000.

${ }^{6} \mathrm{~A}$ probable reason that appetite $(\dot{\varepsilon} \pi \theta 0 \mu$ í $\alpha)$ is present within the list of emotions in $R h$. I 10; cf. infra note 16 .

${ }^{7}$ Cf. MA 8, 702a3-19. For a good discussion of chapters Rh. I 10-13 and the role of emotions in the Aristotelian theory of action and in the forensic context, see Viano 2010. 
reconstruction of an Aristotelian theory of emotions, but merely to put forward an analysis of what I take to be the theoretical starting point for a comprehensive analysis of particular emotions; this is the causal structure of emotions. The importance of clarifying this structure has been pointed at in the literature, and attempts have been made in this direction. ${ }^{8}$ My aim concerning this issue is, first, to contribute to this debate and to clarify some points that have not yet been sufficiently discussed, and, second, to discuss a recent reading about the hylomorphic structure of emotions and its consequence for the problem of the causal interaction between mind and body. I do not assume that every emotion has each one of the four causes I will analyze, and I acknowledge that in each context of discussion some causal aspect of the emotion is stressed over others; but I do assume that the different treatments of emotions in the Corpus are coherent and complementary. Hence, in my analysis of de An I 1 I will take into account and refer freely to the treatments of $R h$. and to other works as well. ${ }^{9}$

In the following pages I will begin discussing the context and ultimate purpose of the presentation of the emotions in $d e A n$. I 1, then I will present a recent 'PostCartesian' reading of the structure of emotions which emerges mainly from these passages of de An.. This reading proposes, in short, to eliminate the problem of the causal interaction between body and soul in Aristotle by resorting to a strong hylomorphism that accounts for the structure of emotions (among other psychophysical phenomena). This will be followed by an analysis of the fourfold causal structure of emotions that also emerges from de An. I 1 and that will be the occasion for discussing the implications that the defenders of the 'Post-Cartesian' interpretation assume for their reading; namely, I will contend that this reading does not really solve the problem of the causal interaction of body and soul. Relying on the analysis of the fourfold causal structure of emotions I will suggest some ideas to demarcate the place where the problem of the causal interaction of body and soul remains in spite of a strong hylomorphism.

\footnotetext{
${ }^{8}$ Most notably by Fortenbaugh 2002, pp. 12-18, with whose discussion I am much indebted, and now also by Rapp 2008, pp. 52 ff. See infra Sect. 9.4.

${ }^{9}$ Aristotle also sees emotions as playing a relevant part in excellence of character, which is characterized precisely as lying in a mean relative to us concerning actions and emotions. In other words, it is the acquired disposition of doing and feeling what is right or appropriate in the particular circumstance of action. In the ethical writings there is not a systematic and unitary treatment of emotions comparable to the one in $R h$., however. From the point of view of practical reason, emotions are also a point of intersection between the rational and the irrational: according to $E N$ I 13, they belong to the irrational part of the soul, which can 'listen' to reason. What does Aristotle exactly mean by this figure is not clear: according to more intellectualist readings, the image means that the irrational part is (or can be) open to reasoned persuasion or admonition apparently each time it feels an emotion (cf. Fortenbaugh 2002, pp. 29-32); other readings focus on the way the rational part 'shapes' the irrational part through early education (cf. esp. Sherman 1989, pp. 162-164, 171-174, cf. 27, 31; cf. Moss 2012, pp. 168-169). I will not deal here with this problem: the place of emotions in relation to excellence and their relation to practical reason falls out of the scope of this article. For a good discussion of this issue, see esp. Sherman 1989, pp. 44-50, 165-174; and the lucid observations of Striker 1996, pp. 293-299 and Nussbaum 1996.
} 


\subsection{De Anima I 1}

In the introductory chapter of $d e A n$., Aristotle leaves clear from the beginning that the study of the soul falls under the philosophy of nature, ${ }^{10}$ i.e. Aristotle will study the soul here as a physicist, 'for the soul is in some sense the principle of living beings'11 (402a6-7).

In this context, immediately previous to the discussion of emotions, Aristotle makes some specific methodological observations that shed light on the ultimate purpose of analyzing emotions. He claims that it is not only useful to know the definition or ' $\tau$ í $\dot{\varepsilon} \sigma \tau \imath$ ' in order to demonstrate from it the accidents ${ }^{12}$ of a substance (as in mathematics), but it is also useful to grasp the essential accidents of a substance, for this contributes in turn to the knowledge of the ' $\tau$ ' $\dot{\text { c }} \sigma \tau \mathrm{l}$ ' (402b16-25). The correct definition of a substance should be one that accounts for those accidents as they appear to us, i.e. it should be one from which these accidents can be demonstrated. Hence, knowing the essential accidents of a substance $x$ gives us an explanandum -or, in more Aristotelian terms, the $\varphi \alpha \imath v$ ó $\mu \varepsilon \nu \alpha-$ that any tentative definition of $x$ should be able to account for. The definitions that lose sight of the $\varphi \alpha \imath \nu$ ó $\mu \varepsilon \nu \alpha$ and 'fail to facilitate even a conjecture about them' are obviously 'dialectical and futile'. ${ }^{13}$ We can assume that, in this treatise, Aristotle intends to reach a definition of the soul that does not suffer from this problem.

Aristotle introduces then the discussion about emotions in 403a2-b19, and it is reasonable to think that he is putting into practice the methodological indication he has just given: he will try to obtain some knowledge, even conjectural, about what he wants to define (the soul) proceeding from some of the $\varphi \alpha \imath v$ ó $\mu \varepsilon \nu \alpha$ that seem to be its essential accidents, namely: its affections $(\pi \alpha \dot{\theta} \theta \eta)$. Thus, the ultimate purpose of the discussion carried out in 403a2-b19 is (a) to state at least a certain sort of psychical phenomenon that the definition he is searching for should be able to explain, and (b) to start to conjecture, with it, about what is soul. If the affections of soul are inseparable from a certain matter, there would be reasons to suppose that the definition of soul should be able to account for this (i.e. that soul itself should be inseparable from a certain matter).

I will divide the passage 403a2-b19 in four main sections.

\footnotetext{
${ }^{10}$ This is a theoretical episteme; for a discussion about the possibility of a full-fledged science of soul, see R. Polansky 2007, pp. 34-5.

${ }^{11}$ All English translations of Aristotle's texts are based on the ROT edited by J. Barnes, with minor modifications.

${ }^{12}$ This is the kind of accidents that belong per se to a substance-for this reason Aristotle calls them 'essential' ( $\kappa \theta^{\prime}$ ' $\alpha$ vó)-, like 'having the interior angles equal to a right angle' belongs to the triangle. These accidents can be demonstrated from the definition of the substance; cf. APo. I 10, 76b12-22; Metaph. V 30, 1025a30-35.

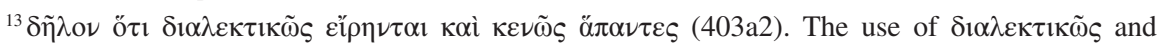

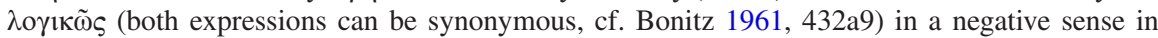
methodological passages is common in Aristotle; cf. GC I 2, 316a8-13, I 8, 325a13; EE I 8, 1217b21; GA II 8, 747b28-30, and esp. 748a13-14.
} 
I) 403a2-16: the difficulty is raised about whether the affections of soul ( $\pi \alpha \dot{\theta} \theta \eta$ $\tau \tilde{\eta} \varsigma \psi v \chi \tilde{\eta} \varsigma$ ) in general are peculiar to the soul or belong to the complex of soul and body (403a3-10). Being the affections essential accidents or properties of the soul, the upshot of this discussion concerns the separability of the soul itself (403a10-16).

II.1) 403a16-28: Aristotle analyses emotions as a particular sort of affection of soul that works as a paradigmatic case in order to answer the difficulty raised in (I). These lines conclude that emotions are a composite of matter and form, and hence that their study belongs to the philosophy of nature.

II.2) 403a29-b16: Aristotle considers which sort of definition of emotions should the philosopher of nature provide.

III) 403b16-19: In the final lines of the chapter Aristotle goes back to the initial difficulty about the affections of soul and draws the final conclusion -based on the discussion about emotions- that they are inseparable from matter in a strong sense: they cannot be separated from the living being's body neither in existence nor in thought (i.e. they cannot even be defined without reference to the body).

In (I) emotions appear as a kind of affection of soul among others. The examples given by Aristotle include anger, courage, appetite, and sense perception in general. ${ }^{14}$ Thus, the term $\pi \alpha \dot{\alpha} \theta o \zeta$ designates any affection of soul, including sense perception ${ }^{15}$ and irrational desires, and not merely a subset of these affections corresponding to what we specifically call 'emotions' ${ }^{16}$ However, after considering the implications of this difficulty for the issue of the separability of the soul, Aristotle reintroduces the consideration of the affections of soul, this time claiming that it seems that all of them (403a16) involve a body, but focusing solely on examples of emotions (anger and fear). I quote the passage II.1) in full:

(i) It seems that all the affections of soul involve a body—wrath, gentleness, fear, pity, courage, joy, and also loving and hating; in all these there is a simultaneous affection of the

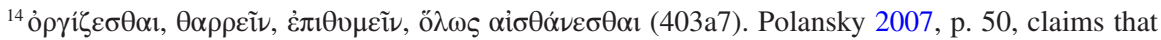
the affections mentioned here are actually operations ( $\left.\check{\varepsilon}^{\prime} \rho \gamma \alpha\right)$ of the soul. All these have in common, also, that they are temporary and not permanent; this is what distinguishes affections from other sorts of qualities according to Cat. 9b28-35, 10a6-10.

${ }^{15}$ Cf. also Cat. 9b5-9.

${ }^{16}$ The case of appetite $(\dot{\varepsilon} \pi \imath 0 \mu \dot{i} \alpha)$ in particular is controversial. Appetite is sometimes mentioned by Aristotle within lists of emotions (cf. for instance EN 1105b21-23, MA 8, 702a2-4) as one of them. Moreover, in Rh. I $10 \dot{\varepsilon} \pi \imath \vartheta \mu$ í $\alpha$ and $\theta u \mu o ́ s$ are mentioned as irrational desires (1369a4) and, as causes of actions, both seem to fall under the class of emotions (as opposed to reasoning) in

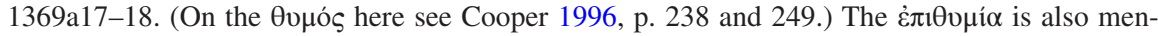
tioned in passing in $R h$. II 1, 1378a3, as one of the factors that can influence judgment, and again in II 12, 1388b32-33 as one of the emotions, alongside anger. One could conjecture that the reason that $\dot{\varepsilon} \pi \imath 0 \mu i \alpha$ and its intentional object (real or apparent pleasure) are discussed within the treatment of $R h$. I 10-11 is that this affection seems suitable to explain why someone performs an action. However, the question remains why, if it is also a factor that affects judgment, $\dot{\varepsilon} \pi \bullet 0 \mu i$ is is not discussed in the chapters $R h$. II 2-11, together with other emotions. However this may be, the debate about the status of $\dot{\varepsilon} \pi \imath v \mu$ í $\alpha$ in relation to $\pi \alpha \dot{\alpha} \theta \eta$ is one of the battlefields of the discussion between cognitivists (or doxastic) and non-intellectualist readings or Aristotelian emotions.
} 
body. (ii) In support of this we may point to the fact that, while sometimes when violent and striking [mental] stimulation $\mathrm{s}^{17}$ occur there is no excitement or fear felt $(\mu \eta \delta \dot{\nu} \nu \pi \alpha \rho \circ \xi \hat{v} \nu \varepsilon \sigma \theta \alpha 1$ iे $\varphi \circ \beta \varepsilon \tilde{\tau} \sigma \theta \alpha \mathrm{l}$ ), on others faint and feeble stimulations move us to these emotions (vं⿰彳े

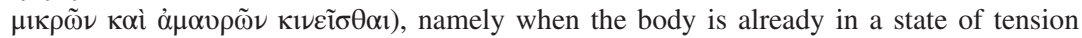
resembling its condition when we are angry. (ii') Here is a still clearer case: in the absence of any external cause of fear we find ourselves experiencing the feelings of a man in fear ( $\dot{\varepsilon} v$

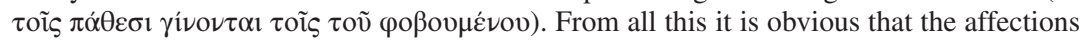

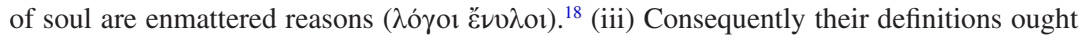
to correspond, e.g. anger should be defined as $(a)$ a certain mode of movement of such and such a body (or part or faculty of a body) by $(b)$ this or that cause and $(c)$ for this or that end. (iv) That is precisely why the study of the soul —either every soul or souls of this sort—is a task proper to the philosopher of nature.' (403a16-28).

Emotions are thus taken in as a paradigmatic case of how an affection of soul happens only when the body undergoes at the same time certain changes. The reason is probably that, in emotions, it appears with special clarity what Aristotle apparently wants to show for every affection: that they are affections $(\pi \alpha \dot{\theta} \theta)$ of the composite. ${ }^{19}$

In (ii) and (ii') Aristotle describes two phenomena that reveal the crucial role that the body plays in emotions. The two cases described in (ii) are aimed to underscore that the sole mental affection, even when it is very strong (say, when we see something very frightening), is not a sufficient cause of an emotion. What Aristotle supposes here, and does not say, is that what is missing in these cases is the corresponding alteration of the body, and this is why we do not really feel fear or excitement although we are in the presence of something very frightening. The same happens when the body is unable to reach a certain temperature, which is needed to have the

\footnotetext{
${ }^{17} \pi \alpha \theta \eta \mu \alpha ́ \alpha \omega \nu$ in $403 \mathrm{a} 20$ must allude to the mental aspect of the emotion, for Aristotle claims immediately that excitement or fear (i.e. the full-fledged emotion) do not happen.

18 'Reason' is one of the (many) possible meanings of $\lambda$ ó $\gamma$ os, and it seems to me that it fits well with the general drift of the passage: the idea is that emotions involve mental states that are due to some cognitive representation (more on this below), and that cannot happen without a body or matter. Another possible translation is 'form', understood as the ontological component of the emotion that corresponds to the soul, and surely Aristotle has this sense in mind also, for in the next lines he goes on to argue that the definition of any emotion should include its form as well as its matter.

${ }^{19}$ In the same line, see Chap. 8, Sect. 8.5, for a detailed analysis of the emotions as particularly clear examples of Aristotle's 'co-dependence of soul and body view'. It is true that in some emotions the physical experience is more distinct than in others. The physical sensations of joy or pity, for instance, seem to be more diffusing than those of fear or anger. However, in general, the bodily alterations that occur when one feels an emotion are a matter of common self-awareness. The paradigmatic value of emotions in $d e A n$. is also not without problems; there is a debate in the literature among spiritualists and literalists about the extent to which these can indeed be taken as a paradigm for every affection of soul, and particularly to sense-perception. While literalists tend to take Aristotle's claims in de An. I 1 seriously and hence consider the physiological component as an essential necessary condition of sense-perception, the spiritualists (notably M. Burnyeat) deny that sense-perception involves essentially a bodily or physiological component, and hence deny the extension of the casual scheme of emotions to every affection of soul; for a good treatment of this debate, see Boeri 2010, pp. cxxxvii-cxlvii.
} 
corresponding emotion. ${ }^{20}$ This suggests that the bodily or material aspect of the emotion is a necessary condition for it to happen. ${ }^{21}$ In the second example, in turn, when the body is already in a state close to what its condition is when we are afraid or angry, a feeble stimulation can trigger the emotion in question. ${ }^{22}$

The fact that emotions are also affections of the body is particularly clear, says Aristotle, from (ii') the fact that we come to have the same affection than someone who's scared, even when there is nothing to fear. The reason that we can claim we have the same affection than -or are in the same state than-someone who's scared, but without being scared-given that there is no object perceived as frightening-is a certain state of our body. Here, just like in the previous example, we do not feel the full-fledged emotion, only that in this case the element missing is not the bodily one, but the mental one. The examples (ii) and (ii'), thus, show a little more than Aristotle initially announces: they not only make clear that emotions have a necessary bodily component, but they also show that a certain mental representation or intentional content (of something as frightening, for example), is another necessary condition for there to be a full-fledged emotion.

It is not a surprise, then, that Aristotle concludes this analysis introducing the

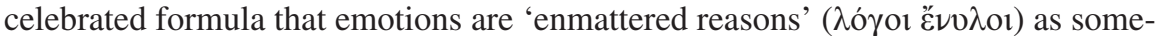
thing evident $(\delta \tilde{\eta} \lambda \mathrm{o \nu})$. Hence, their definition should include both matter and reason (or form). Before analyzing the definition offered in (iii), let me make one minor comment about the further conclusion that Aristotle draws form the passage: that 'the study of the soul-either every soul or souls of this sort-is a task proper to the philosopher of nature.'

That the philosopher of nature must study the soul is also especially stressed in $P A$ I 1, esp. 641a17-641a32. ${ }^{23}$ However, the point of PA I 1 and of de An. I 1 seem to be different. In $P A$ I 1 Aristotle is discussing against the materialist approach for the explanation of the parts of animals, and the point of the assertion about the soul as the main object of study of the physics is to stress the fact-against materialismthat matter is not its main object. In other words, that there must be a priority of form over matter in natural explanations. In $d e A n$. I 1 the drift of the passage seems

\footnotetext{
${ }^{20}$ This condition is not met when the body has the opposite temperature to that required by the emotion, either by the influence of another emotion or due to an illness, age, etc. For this reason Aristotle claims in $R h$. II 13, 1389b29-32, that old people are more prone to feel fear than young people (the old men's body is usually cold because of their age, as fear requires it to be; while young people are normally warmer). References to the bodily temperature that belongs with differ-

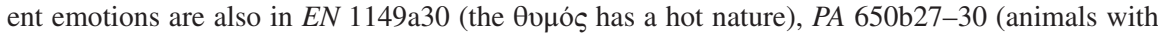
watery blood are cooler and hence more prone to feel fear), Resp. 479b19-26 (fear is associated with a cooling of the heart). There is also an interesting suggestion in EN 1178a14-16 that some excellences of character are also due to the body, and cf. also 1178a19-21, quoted below in section $4(b)$.

${ }^{21}$ Cf. 403b1-3.

${ }^{22}$ From this passage it already emerges that what triggers the emotion, including the movement of the body involved in it, is in the last term a mental or representational stimulation (more on this below).

${ }^{23}$ Cf. also Metaph. Z 11, 1037a16-17.
} 
to be quite the opposite: the initial question is not whether matter can explain psychic events, but whether the affections of the soul involve a body or not, and to what extent they do. And the burden is clearly on the side of the affirmative answer. This explains the methodological passage that precedes the discussion about emotions and affections in general, and the suggestion that any definition of the soul that leaves these affections without an explanation (i.e. that does not take into account the peculiar relation of the soul with a body of a certain kind) is "futile and dialectical' ${ }^{24}$ This is why the claim that the soul is an object of study of the philosopher of nature, and the remarks about the sort of definition appropriate to this object, emphasize its non-separability from a body, and they should be likely read in the light of some passages of $P h$. II 2 where he discusses the formal object of the philosophy of nature in contrast with mathematics. ${ }^{25} \mathrm{I}$ will comment on this briefly for it is especially relevant for the reading presented in section 3.

One of the main tasks of $P h$. II 2 is to argue that the philosopher of nature should not study the form of natural beings separated from movement -i.e. from matter-as those who postulate the Ideas believe (cf. 193b35-194b1; 194a5-7). ${ }^{26}$ This does not mean merely that these forms cannot exist but in some matter (the same happens with mathematical objects such as lines or spheres), but it should be understood in the strong sense that the forms that the philosopher of nature studies cannot even be conceived of without their matter. Hence the definition of these forms cannot omit to mention their matter. According to Metaph. Z 11 this is precisely the difference between composite entities like a bronze circle, and a man. While bronze is accidental to being a circle, and hence the circle can be defined without mentioning the matter in which it necessarily exists, 'an animal is something perceptible, and it is not possible to define it without reference to movement—nor, therefore, without reference to the parts and to their being in a certain state' (Metaph. Z 11, 1036b2830 , cf. 1036b3-4).

That this is precisely the way in which Aristotle proposes to understand the relation between soul (form) and body (matter) in emotions and in affections in general, finds confirmation in the final lines of $d e A n$. I 1: 'the affections of soul, insofar as they are such as passion and fear, are inseparable from the natural matter of animals in this way and not in the same way as a line or surface.' (403b16-19). For this reason, Aristotle claims in (iii) that the definition of emotions that the philosopher of nature should give must include their formal aspect as well as their material aspect. Before discussing with some detail part (iii), I will present an interesting recent reading, that I will discuss in the remainder of this article.

\footnotetext{
${ }^{24}$ This seems to be precisely the methodological error former thinkers made when studying the relationship between soul and body, according to Aristotle (cf. de An. I 3, 407b12-25).

${ }^{25} \mathrm{Cf}$. Charles 2011.

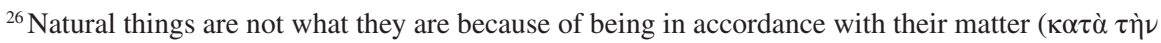
ט๊ $\lambda \eta \nu$ ), but that does not mean that they can be what they are without that particular matter (ov้ $\tau$ '

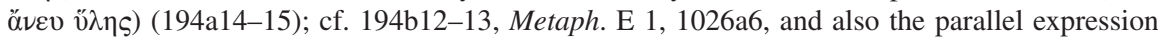
about matter as hypothetical necessity in $P h$. II 9, 200a 5-6, 8-10.
} 


\subsection{A Reading against 'Post-Cartesian' Readings}

Recently, a radical interpretation has been proposed by Ch. Rapp ${ }^{27}$ and D. Charles ${ }^{28}$ about the Aristotelian conception of emotions and its consequences for the problem of the causal interaction of body and soul in Aristotle. These authors argue against the 'two component' readings of Aristotelian emotions. The distinctive feature of the two component reading is that it considers that the emotion is a combination of a purely psychical component (that is mentioned in what Aristotle calls the dialectical definition of the emotion) and a purely physical component (that is mentioned in the physical definition). Against this tenet, Charles claims that being angry and being afraid are 'common to body and soul' in a particularly demanding way: 'The relevant processes are inseparable in definition into two separate components. There is not one (definitionally) separable purely formal process to which can be added another definitionally distinct physical (or bodily) process, both making (definitionally) separable but individually necessary contributions to the outcome. ${ }^{29}$

In the same vein, Rapp points out that if one takes into account the component expressed in the 'formal' part of the definition, then the emotion is caused by a perception or by a $\varphi \alpha \nu \tau \alpha \sigma i \alpha$, and both of them are themselves psychophysical phenomena for Aristotle, and not purely mental or psychical phenomena. ${ }^{30} \mathrm{D}$. Charles argues similarly that the 'dialectical' definition of the emotion, that expresses its form, states that the emotion is a desire (ó $\rho \varepsilon \xi_{1} \varsigma$ ) (in the example: of revenge), but desire is itself also an inextricably psychophysical phenomenon, ${ }^{31}$ for desire is not merely the mental act of intending an object as an end, but it is also the heat that happens in the body with it. ${ }^{32}$ On the other hand, concerning the purely physical component, both Rapp and Charles deny its pure nature pointing out that the boiling of the blood around the heart is itself described in teleological terms, and that the fact that it has that end is what makes that movement of the blood a determinate emotion and not any other. ${ }^{33}$ In sum, both components of emotions are already psychophysical processes, both involve soul and body.

There is a further, relevant conclusion that these authors draw form this reading of Aristotle's conception of emotions and affections of soul in general, namely that

\footnotetext{
${ }^{27}$ Rapp 2006.

${ }^{28}$ Charles 2011.

${ }^{29}$ Charles 2011, p. 81.

${ }^{30}$ Cf. Rapp 2006, p. 205, and Charles 2011, p. 76.

${ }^{31}$ Charles 2011, pp. $82 \mathrm{ff} .$. It should be noted, though, that not all the emotions are defined (or easily understood) as desires. Actually, the only emotion explicitly defined in $R h$. as a desire (öp $\rho \xi 1 \varsigma$ )

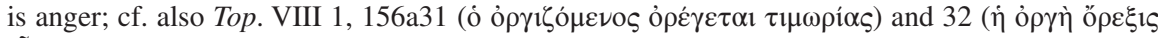

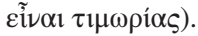

${ }^{32}$ Cf. MA 8, 701a33ff.

33 ' [W] hat happens in the ensouled body when the blood starts to boil is not due to the laws of elementary change, but rather something that only happens in a specific body formed by a specific sort of soul' (Rapp 2006, p. 205). Cf. Charles 2011, p. 79.
} 
it eliminates the problem of the causal interaction between soul and body, which affects what they call 'post-Cartesian' readings. ${ }^{34}$ The reason is that Aristotle does not divide these phenomena into two pure separate components. Hence, there is no need to relate these components through causal interaction. 'The idea of such an interaction between body and soul does not occur until we think of the soul as a more or less separate entity.... ${ }^{35}$

This interpretation is certainly appealing. However, I am not sure that it solves the problem it claims to solve. To start with, at first sight it seems that the problem of the causal interaction between body and form/soul is transferred to each of the psychophysical components of the emotion. ${ }^{36}$ But I will focus on other issues that seem to have been overlooked by this reading, and which concern the fourfold causal structure of emotions. This will allow me to circumscribe the diverse aspects of the problem of the causal interaction between mind and body in the emotions in Aristotle. Besides that, an analysis of the Aristotelian causal approach to the emotions may have worth in itself as a promising model to tackle some issues that concern the causal and intentional aspect of emotions.

\footnotetext{
${ }^{34}$ As D. Charles defines them, post-Cartesian readings hold the two component reading, i.e. they understand that there is a purely mental item and a purely corporeal item which interact. Among the 'familiar options' of post-Cartesian philosophy Charles counts dualism, materialism, functionalism and spiritualism (cf. Charles 2011, p. 76). Aristotle's position would be a radical alternative to all these, according to this author. A contemporary version of this sort of reading in experimental psychology is the theory of emotions of Schachter-Singer, which sometimes is actually called the 'two factor' of 'two component' theory of emotion.

${ }^{35}$ Rapp 2006, p. 207. This author claims, moreover, that this is an intentional move on Aristotle's part: 'Since Aristotle ... pleads ... for the model of emotions as psycho-physical units it seems safe to conclude that he deliberately avoids a setting which allows of causal interaction between body and soul.' (207). A lucid analysis showing that Aristotle in fact perceived this causal interaction as a problem can be found in Chap. 8 in this volume.

${ }^{36} \mathrm{~A}$ necessary condition for this reading to hold is that the components of the emotion have themselves no purely physical and mental components; against this last tenet see the critical arguments of Caston 2008, pp. 30-49. Charles 2011, pp. 87-89, has an argument to defend himself against this objection, for he pleads that the connate pneuma (which extracts and expands thanks to the heat / cold that accompanies desire, thus causing bodily movements, cf. MA 10, 703a9-24) is also itself an inextricably psychophysical phenomenon and its movements cannot be defined without reference to its goals. I'm not sure that Charles argument works, for it seems to put on the same level psychophysical phenomena involving mental events as formal causes (such as desire), and psychophysical phenomena which do not involve a mental event as its formal cause (such as the movements of pneuma in the processes of nutrition and reproduction). This becomes more problematic, I think, if one remembers that Aristotle's explanation of the matter's movements in general (and not only of organic matter) is not mechanistic but rather qualitative, so that a teleological dimension of a movement is not a warrant of the presence of soul (much less of mind).
} 


\subsection{The Causal Structure of Emotions}

In this section I will analyze the causal structure of Aristotelian emotions, following the Aristotelian theory that there are four kinds of cause, each of which consists in a different (and irreducible) relation of causal dependence. ${ }^{37}$ Beyond the discussion with this recent reading, the schematic analysis proposed of the fourfold causal structure of emotions is also intended as a hermeneutical starting point for a comprehensive analysis of particular emotions in Aristotle. The idea of an organized concurrence of several kinds of causes as necessary - but not separately sufficientconditions of emotions seems indeed a promising way of approaching this complex phenomenon, and accounting for its diverse aspects.

In de An. I 1 we already find an indication of the fourfold causal structure of emotions. Throughout this text form and matter of the emotion are explicitly discussed, and in Aristotle's exemplary scheme of how the definition of an emotion should be in 403a25-27, the four causes are already alluded to. I reproduce the text again:

Consequently their definitions ought to correspond, e.g. anger should be defined as (a) a

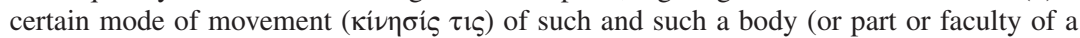

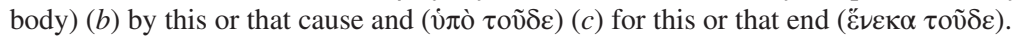

(a) Matter and form as causes.

In part $(a)$ of the exemplary definition both matter and form are implied. The emotion is not merely the movement of any matter, but the movement of a certain body: an animated or ensouled body. Hence both matter and form are the simultaneous causes of this movement. ${ }^{38}$ Soul and body are both affected when an emotion happens, and to feel an emotion is to be affected as an animated or ensouled body. In this sense, the movement that is the emotion is a psychophysical phenomenon, without any of the two items (matter or form) causing the other in an efficient sense. In similar cases, in fact, Aristotle sometimes refers to these causes as 'elements', ${ }^{39}$ for they are immanent to the item in question.

This is also coherent with the general characterization of emotions in $R h$. II 1:

'Emotions are those states through which people, being altered, turn about their judgments;

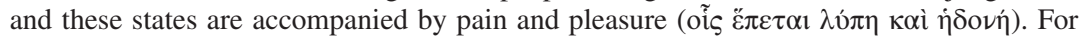
instance: rage, compassion, fear and all the like, and their contraries.' (1378a19-22).

\footnotetext{
${ }^{37}$ The discussion in Fortenbaugh 2002 is an important antecedent of this sort of reconstruction. This author emphasizes the role of beliefs and opinions as the efficient cause of the emotion based on passages of Top., APo and of course Rh. II, along the formal and material causes presented in de $A n$. I. After his seminal work, there has been much debate about whether it is opinion or $\varphi \alpha \nu \tau \alpha \sigma i \alpha$ that have this role. I will refer to this debate below. Rapp 2008, p. 52, also acknowledges that the causal structure of emotions should be analyzed from the Aristotelian perspective of the four causes, but his subsequent analysis is restricted to only to two of them: form and matter.

${ }^{38}$ For a different reading, see Rapp 2006.

${ }^{39}$ Cf. Ph. I 1; I 6, 189b 16, 27-29; Metaph. XII 4 passim.
} 


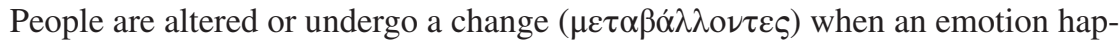
pens. ${ }^{40}$ Thus, emotions seem to be described in general terms as a change or alteration (a sort of movement) of the composite (i.e. person) that feels the emotion. And the occurrence of this change is what makes them turn about their judgments. ${ }^{41}$ Being an alteration of the composite is certainly a feature common to other affections of soul, as perception (at least, according to de An. I 1). What seems to be specific about emotions is that they are always accompanied by some sort of pleasure and/or pain. ${ }^{42}$ This is in coincidence with the general characterization of emotions in EN II 1105b21-23: 'by emotions I mean appetite, anger, fear, confidence, envy, joy, love, hatred, longing, emulation, pity, and in general the feelings that are

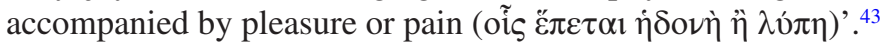

Aristotle understands that there is a priority of the form over matter as a cause, and this is expressed notably in the concept of hypothetical necessity. ${ }^{44}$ But this priority of form over matter, at least within one natural living being, does not happen necessarily in the manner of efficient causation, and does not involve temporal precedence. These causes are usually simultaneous. Both matter and form happen at the same time in a living being and act as reciprocal causes, one as potency and condition of possibility, the other as first actuality. I suggest that we should understand under this model what happens in emotions with form and matter as causes.

From the example given by Aristotle in de An. I 1 of what he considers to be a definition that takes into account only the form of the emotion (a definition that he calls 'dialectical'), we can infer which is the cause-form of the emotion, at least in the case of anger: the dialectician 'would define e.g. anger as the appetite (ó $\rho \varepsilon \xi 1 \varsigma$ ) for returning pain for pain, or something like that' (403a30-31). Thus the form of

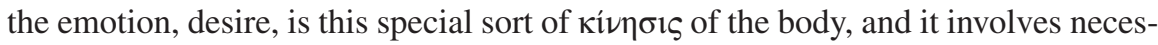
sarily an intentional object. Hence, the form-cause of anger is a certain desire, appetite or longing for $x$. Following the example, $x$ can be formulated as a proposition

\footnotetext{
${ }^{40}$ This is essentially the same claim Aristotle makes in de An. I 4, 408a34-408b18: it is the man who experiences these things (being bold or fearful, being angry, etc.).

${ }^{41}$ Probably for this reason, Aristotle claims that arousing emotions in the audience is especially useful in forensic oratory, i.e. when the orator tries to influence judges when he defends or charges somebody with a crime (Rh. II 1, 1377b29-1378a5; cf. I 2, 1356a15-16; 1354b3-11). Due probably to the physical alteration the involve, they also have a distorting effect on sense-perception, cf. Insomn. 460b3-11 (for a good discussion of this passage see Leigthon 1996).

${ }^{42}$ This is not as easy to detect in every emotion described by Aristotle; the clearest counterexample is hatred (cf. $R h .1382 \mathrm{a} 11-13$ ). There has been some debate about whether pleasure and pain are the genus of emotions (as it happens in Plato's Phlb.) or not; D. Frede 1996 has argued for this reading which is also endorsed by Cooper 1996, but the majority of interpreters nowadays are inclined to think that Aristotle abandoned the Platonic position on this point, even when pain and pleasure are important components of emotions (cf. for instance Dow 2011, Moss 2012, Rapp 2013).

${ }^{43}$ Cf. EN II 1104b14-15.

${ }^{44}$ This sort of priority is not usually expressed as the form vं $\pi$ ò $\tau o \tilde{v} \delta \varepsilon$ matter happens, for this reason I understand that form is not in part $(b)$ of the definition, but is together with matter in $(a)$.
} 
(this is even clearer from the discussion of $R h$. II). It is important to underline that the form-cause is not $x$ but the desire for (or the aversion against) $x .^{45}$

On the other hand, we have the matter-cause which is stated in the definition that Aristotle ascribes to a physicist in de An.: 'a boiling of the blood or warm substance surrounding the heart' (403a31-b1). This material aspect of the emotion does not happen as a consequence of the longing or desire, but is part of what it is to desire. As it is part of weaving to move your hand. ${ }^{46}$ The relation between both definitions and the elements identified in each is spelled out as follows: 'The one assigns the material conditions, the other the form or account; for what he states is the account of the fact, though for its actual existence there must be embodiment of it in a material such as is described by the other' (403b1-3). It is clear, then, that matter and form are simultaneous causes of the emotion as different constituents of the phenomenon.

Now, as it is clear, the readings of Rapp and D. Charles are focused on these two causes. When these authors claim that emotions are a psychophysical phenomenon they are considering the inextricable relation between matter and form as its constituents. However, the problematic point for the causal interaction of soul-or more precisely, mind-and body emerges in a more pressing way with the other forms of causality involved, which also appear in the exemplary definition of anger in de An. I 1, and for which I am not sure that their reading provides an answer.

(b) What initiates movement or the efficient cause of emotion.

In $(b)$ Aristotle refers to the cause due to which (írò $\tau$ oṽ $\delta \varepsilon$ ) the movement in $(a)$ occurs. This is the principle of movement or efficient cause of the emotion, what motivates or triggers the emotion.

There are clues of this sort of moving cause in at least two other passages in which Aristotle is discussing the four causes: Ph. II 7 198a19-20, and APo II 11, 94a36-b5. The example is the same in both cases. In it, Aristotle explains that the Persians went to war against Athens due to a previous Athenian attack on Sardis, which (Aristotle does not say but presumably) was taken as an offense or wrongdoing by the Persians. What is remarkable about this sort of efficient cause is that we would describe it as a reason. It is an efficient cause of a war, because it provoked it, and it provoked it because the relevant agent of the movement perceived that fact and judged it in a determinate way (e.g. as a wrongdoing), and reacted to it accordingly. Being this reaction (probably the desire of revenge or retaliation) the proxi-

\footnotetext{
${ }^{45}$ Anger is defined as a desire in Rh., in de An., and also in Top. VIII 1, 156a32-33. Of course, this is not the only case: in $R h$. I 10, emotions are closely linked to irrational desires, such as appetite (for the discussion about غ̇лı $\theta 0 \mu$ í see supra note 16), and the reason is probably that emotions are considered in this chapter as probable causes of actions. This accent on their motivational role accounts for their being treated as desires, for desire (rational or irrational) is the efficient cause of

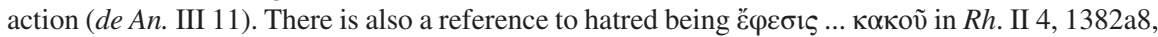
and to friendly feelings as wishing ( $\beta o v ́ \lambda \varepsilon \sigma \theta \alpha i)$ for someone what one deems good (1380b36-37). I admit that it is not easy, though, to reconstruct every emotion or feeling as a desire for something (even when it is possible to say that all emotions have intentional objects).

${ }^{46} \mathrm{Cf}$. de An. I 4, 408b11-13. For the bodily aspect of emotions also in Rh. see supra note 20.
} 
mate efficient cause of the action. In Top. VI 13, 151a15-6 we find the same claim.

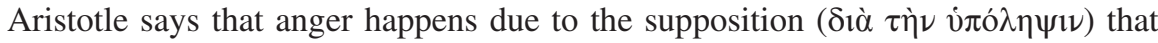
one has been demeaned, so that the moving cause of an emotion appears to be certain sort of representation or belief.

In $R h$. II this is largely confirmed, as is well known. ${ }^{47}$ Aristotle organizes the discussion of each particular emotion around three main aspects that the orator should know if he is to arouse a particular emotion in the audience (cf. 1378a23-

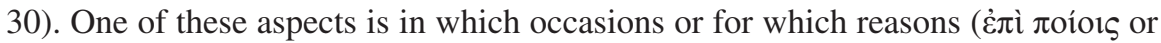
$\delta ı \grave{\alpha} \pi$ oí $\alpha$ ) people have a determinate emotion. ${ }^{48}$ Under this heading, Aristotle offer a survey of evaluative beliefs or representations of situations and persons, for instance, it is to see a situation as dangerous that produces fear, to understand certain attitude as a wrongdoing o as insulting that causes anger, etc.

Being the proximate moving cause of an emotion, it is clear that, for good reasons, this is one of the aspects in which the detailed discussion of emotions in $R h$. II is primarily focused: how to present the audience with a situation or person as bearing the key feature to trigger the desired emotion towards her/it. In other words, the orator is provided with information about how to produce in the audience the representation $(\varphi \alpha \nu \tau \alpha \sigma i \alpha)$ or the belief that is the first moving cause of an emotion. ${ }^{49}$

In this description of the efficient cause of the emotions I have been dodging a controversial issue concerning the exact nature of the mental event that triggers the emotion; more precisely whether it is a belief or a $\varphi \alpha \nu \tau \alpha \sigma i \alpha$ in the technical sense of de An. III 3, i.e. something that the agent imagines or a quasi-perceptual experience that strikes him, but that he does not necessarily judges true. The fact that Aristotle's terminology in $R h$. II at some points oscillates between both is probably one of the causes of the controversy, although the debate is philosophical in nature. Those who defend a doxastic reading of emotions, claim that the efficient cause must be a belief of the agent, i.e. something that he deems true. ${ }^{50}$ The terminology of imagination present in these chapters of $R h$. II is explained away by this reading as referring to an apparent truth (i.e. the agent has a belief which causes the emotion, only that it is mistaken), so that the technical distinction between $\varphi \alpha \nu \tau \alpha \sigma i \alpha$

\footnotetext{
${ }^{47}$ The role of a representational factor as the moving cause of the supra emotion is mostly uncontroversial. There is a standing debate, though, about the exact nature of this representation, especially about whether it is a $\varphi \alpha \nu \tau \alpha \sigma i \alpha$ or a belief. More on this below. Given the closeness between rhetoric and dialectic, some authors claim that the treatment and definitions of emotions of $R h$. II are dialectical (cf. Cooper 1996; and esp. Rapp 2006) in the sense that Aristotle describes in de An. I 1; i.e. that they pick up only the form-cause or account of the emotion. A closer look at the matter shows that it is really the moving cause that is mainly discussed in $R h$.

${ }^{48}$ The causal vocabulary to refer to this factor in these chapters of $R h$. II appears more than once (cf. for instance 1380a1, 1380b35, 1388b29). This cause of the emotion is often referred to as the object of the emotion (for instance: what is feared, hated, etc.).

${ }^{49}$ Cf. esp. MA 7, 701b16-23, Ib. 8, 701b34-702a7, and esp. 702a17-19 for the role of $\varphi \alpha \nu \tau \alpha \sigma$ í $\alpha$ in the production of emotions.

${ }^{50}$ Some places where verbs associated with intellectual assent are mentioned as the trigger of emotion are $R h$. II 1378b2, 1382b31-34, 1383a26, 33, 35, 1385b20-22 (diverse forms of oóo $1 \alpha \mathrm{l}$ ),

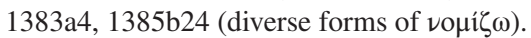


and belief is not at issue in these chapters. ${ }^{51}$ The main point of this reading, especially represented by Fortenbaugh, is that, if emotions involve a doxastic ingredient as one of its causes, then they are not an essentially irrational phenomenon and they depend ultimately on a capacity proper of human beings. ${ }^{52}$ On the other hand, the 'phantastic' reading of emotions argues that when Aristotle mentions $\varphi \alpha \nu \tau \alpha \sigma i \alpha$ as the cause of the emotions he is to be taken at face value; i.e. that he is using the term in its technical sense, as distinct from belief. ${ }^{53}$ Given that imagination or $\varphi \alpha \nu \tau \alpha \sigma i \alpha$ is common to animals, for it derives from perception,,$^{54}$ this reading purports a radical de-intellectualization of emotions. It is not necessary, in order to have an emotion, to believe or judge that a certain evaluative representational content is true, but merely to have a quasi-perceptual evaluative image of it. One of the recent authors to argue for this interpretation, J. Moss, recognizes still that some emotions are caused by beliefs, as it appears from various passages of $R h$. II (see note 50), but she argues that: 'Passions can result from beliefs, because the thinking which leads to belief is supplemented by visualizing or other exercises of $\varphi \alpha \nu \tau \alpha \sigma i \alpha$ [such as anticipation or memory]; passions normally entail beliefs, because the $\varphi \alpha \nu \tau \alpha \sigma i \alpha 1$ on which they are based normally trigger beliefs' ${ }^{55}$ However, since emotions are not functions of belief, according to this reading, they are irrational.

I will not take sides on this debate here, since for my purposes in this article it makes no difference whether the emotion is triggered by a belief or a $\varphi \alpha \nu \tau \alpha \sigma i \alpha$ understood as a quasi-perceptual representation, in both cases it is the content of an evaluative representation that is the efficient cause of the emotion, which is all I need for my argument.

Let us now go back to the problem of the causal interaction between mind and body, which non-Cartesian readings intend to eliminate. Given that the efficient cause of the emotion is an intentional object (whether of a $\varphi \alpha \nu \tau \alpha \sigma i \alpha$ or of a belief) of evaluative nature, hence the problem of the causal interaction between mind and body seems to be still there and is not eliminated by the fact that there are not really two pure components of the emotion. For even if there are not two pure components or elements of the emotion, there is at least one cause of the emotion which precedes the emotion, and which is intentional. Of course, this cause, which is the content of a representation, cannot happen without a body; but it appears to be the intentional nature of this psychophysical act, its particular content, what causes (as a moving

\footnotetext{
${ }^{51}$ Cf. Fortenbaugh 2002, 96-97; Nussbaum 1996, p. 307.

${ }^{52} \mathrm{Cf}$. Fortenbaugh 2002, passim; Boeri 2007, pp. 258-260.

${ }^{53} \mathrm{Cf}$. de An. III 3, 428a18-b9. Some places where $\varphi \alpha \nu \tau \alpha \sigma i \alpha$ and derivatives are mentioned as the trigger of emotion are $R h$. II 1382a21,25,28, 1383a17, 1385b13, 15-16, 1387b23, 26. In Aristotle's treatment of pleasure found on $R h$. I 11, $\varphi \alpha \nu \tau \alpha \sigma i \alpha 1$ are more clearly given a central role. Around twelve sources of pleasure (mentioned for the orator to be able to arouse that sensation in the hearers) are mentioned, and in at least four of them a $\varphi \alpha \nu \tau \alpha \sigma \sigma^{\prime} \alpha$ is the cause of the subsequent pleasure; cf. 1370b33-34, 1371a9, 1371a19-20.

${ }^{54}$ Moss 2012, pp. 72-73, argues accordingly that animals also feel emotions according to Aristotle, against Fortenbaugh 2002, who denies this.

${ }^{55}$ Moss 2012, p. 99. This author presents a strong and well argued 'phantastic' reading (cf. esp. Moss 2012, pp. 69-99). Cf. also Cooper 1996, pp. 246-247; Striker 1996, p. 291.
} 
cause) the particular emotion. I cannot see why not to affirm that the evaluative content of these representations has causal preeminence over the phsychophysical aspect of the emotion in question. For it is a representation of something as dangerous, as a wrongdoing, etc, that accelerates our pulse, gives us cold sweat, etc. and makes us desire revenge, flee, etc.

Hence, my suggestion is that in emotions there are (1) two simultaneous causes, matter and form, that are inseparable even in definition. Although there is a priority of form over matter, this priority is non-temporal. These two causes, form and matter, are represented respectively by the desire (as a pro-attitude towards an intentional object $x-x$ being the final cause, that I will discuss in the next subsection) and by the movements of the body without which this sort of desire cannot happen. (2) There is a causal and temporal priority of the efficient cause, which is the evaluative content of a representation that triggers the emotion. This is clear from the treatment of emotions in $R h$. II, which assumes as evident that emotions can be triggered through speech, which confirms the-in Aristotle's view-efficient priority of the content or intentional object of a mental act over the psychophysical one. ${ }^{56}$

Charles' and Rapp's reading only takes into account two of the four causes of emotions, namely matter and form. If my analysis is correct, though, when we include all the four causes into the picture, then the causal interaction of mind and body remains part of the Aristotelian emotions, independent of how strongly the hylomorphism of emotions is understood. This also shows that the question about the causal interaction between soul and body in Aristotelian emotions is more complex than it seems at first sight, because 'causal interaction' can be taken in more than one sense, and not only in the efficient one.

Before moving to the last cause, I want to comment briefly on another aspect that the orator should know according to $R h$. II $1,1378 \mathrm{a} 23-30$, and that does not seem to fit into any of the four causes, but points to a relevant matter concerning the conditions under which a certain emotion can be triggered. This is in what personal

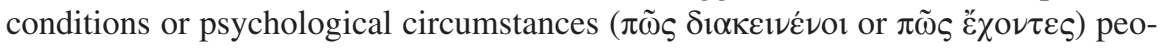
ple tend to feel a particular emotion. Most of these have to do with beliefs and frames of mind that are related to certain situations (illness, poverty, etc.), to certain personal factors (like age), to certain physical estates (i.e. to the material cause of the emotion), and also to the character of the person.

What I find especially important from this set of considerations of $R h$. is that they bring to the foreground a new and relevant aspect which was absent in de An I 1 . This is the character as having a crucial role in the arousal of any emotion, so that there is not a necessary or mechanical causal link between a set of possible inputs and an emotion. One and the same speech may not have the same emotional effect in every member of the public. The mediation of character in this respect can be understood in this way: the moral character determines how one and the same fact or situation is evaluated by an agent, so that, presented with the same 'input', two

\footnotetext{
${ }^{56}$ D. Frede 1996, p. 272, puts it very perspicuously: 'In short, we try to change the people's beliefs, rather than their temperature, because a change of belief will also change their feelings.' Cf. also Nussbaum 1996, p. 305.
} 
agents with different characters would have different emotional reactions because they would have different evaluative representations of it. For instance, the presence of a mouse in the house, can be evaluated by John as dangerous (who then freaks out about it) and by Francis as mere inconvenience (who then calmly places mousetraps). All indicates that the character determines ultimately the intentional object of the emotion (since it entails an evaluative component) and hence the emotion felt. Those who endorse a doxastic reading of Aristotle's emotions, naturally tend to understand that the character depends mostly on the agent's practical beliefs. However, even if certain beliefs are part of one's character, it is true that the excellences of character are located by Aristotle in the irrational part of soul, which can listen to reason, but it is not itself rational. In connection to this, Aristotle insists in EN II 2-3 that the excellences of character are referred to pleasure and pain, giving mainly examples in which corporal and irrational pleasures are involved. There is also an interesting suggestion in EN X 1178a14-16 that some excellences of character are also due to the body, and also the explicit claim that 'being connected with the passions also, the moral excellences must belong to our composite nature' (1178a19-21), i.e. to the fact that we are an ensouled body end not merely an intellect. If these suggestions are to be taken seriously, then probably the moral character of an agent is closely related to the nature of the compound ( $a$ ) as a cause of the emotion.

(c) The end or 'that for the sake of which'.

Using the example of anger, Aristotle claims in $(c)$ that the definition of an emotion

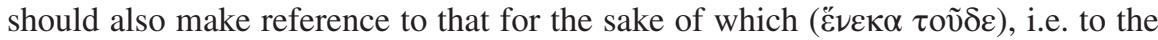
end. In the case of anger, this is the object of the desire: the formal cause of anger is the desire of $x$, the final cause of anger is $x$. From this it is clear that this cause has to be simultaneous with the formal and the material one. And the intentional content of $x$, that is stated as a proposition, is clearly an essential part of which the emotion in question is. It is also clear in anger that the content of $x$ has a direct relation to the content of the efficient cause of the emotion: moreover, that content is determined by the content of the efficient cause. If I think that Bill has offended or demeaned me, I get angry, i.e. I have a blood boiling type of desire for revenge against Bill. In the case of anger, thus, the end is clearly the revenge against the individual that I think, believe, or imagine, has offended me.

As I just mentioned, in $R h$. II Aristotle organizes the discussion of each particular emotion around three main aspects that the orator should know. The third of these

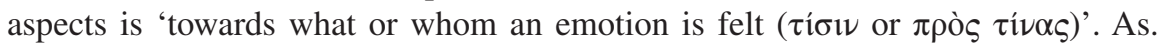
A. Kenny has noticed, in Aristotle's treatment of emotions this is the closest we find to the intentional object of the emotion. ${ }^{57}$ This aspect of the emotion is usually considered in $R h$. II together with the aspect that I have identified with the efficient cause of the emotion, and for good reasons: they are clearly correlative. I don't want revenge from any one at random but from he who I think has offended me; I don't

\footnotetext{
${ }^{57}$ For the object of emotions cf. Kenny 2003, pp. 131-141. For Aristotle's anticipation of the concept of formal object of an emotion in Rh. II see Kenny 2003, p. 135.
} 
fear any one at random but her that I think can harm me. To this extent one could think that this also alludes to (or is part of) what in de An. I 1 is the end of the emotion. The reason is that, if an emotion involves a desire of $x$, and $x$ is the final cause of the emotion, and $x$ appears necessarily under a description which is correlative to the efficient cause that motivated the emotional response, then the person or thing towards what or whom an emotion is felt is part of that description of the final cause $x$. In this sense it can be understood the traditional conception that the object of the emotion coincides with its cause. To be more precise, it should be added that it is correlative to its efficient cause, but that there are more causes than this that can have more or less preeminence in particular circumstances, as Aristotle acknowledges when he considers in $R h$. II in what personal conditions or psychological

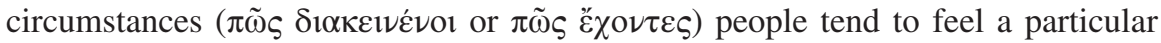
emotion (cf. supra). Matter, for instance, is a cause as a condition of possibility, that sometimes can have such a strong preeminence as to be picked out as the cause of the emotion in a given circumstance, for instance, when someone, being drunk, gets angry at an insignificant offense (cf. the analogous example in $R h$. II 2, 1379a1619). In this case, the material cause of the emotion is not the same as its object, but its efficient cause understood as the evaluative (however mistaken) representation is still formally correlative to the object.

In anger, as well as in the emotions presented as causes of actions in $R h$. I 10 , there is a recognizable end that eventually leads to an action. However, in other emotions presented in $R h$. II the final cause or end is not necessarily clear, especially when they are not defined in terms of a desire. Noticing this, Fortenbaugh claims that there are practical and non-practical emotions, in the sense that the ones that have an end tend to lead to action. ${ }^{58}$ Even if this is correct, the fact that some emotions do not lead to action does not exclude their having an end, i.e. their being intentional in the sense of aiming affectively to an object. Although they do not appear in the definition of emotions in de An. I 1, we may guess that both the pleasure and the pain that go together with emotions account partly for this dimension. The reason is evidently that we usually desire what we think is pleasant or will lead to some sort of pleasure, we want to avoid what we perceive or anticipate as painful, and we desire what we think will relieve us from a present pain. ${ }^{59}$ This seems confirmed by the fact that not every desire leads necessarily to action, as Aristotle recognizes in EN III 1111b23-24: we can wish things that we cannot accomplish on our own, and we can even wish the impossible, like being immortal. Another instance of a desire of an impossible end can be reconstructed in shame, for the object of my shame can be well described as something that I wish I had not done. So not every desire leads to an action, but still every desire is aimed at an object. This is the same as saying that desire is intentional, and given the peculiar propositional attitude that is desire, its intentional object can be described as an end

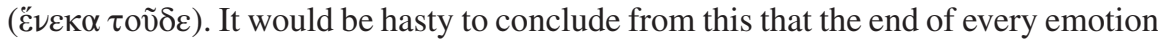

\footnotetext{
${ }^{58}$ Cf. Leighton 1996, p. 211.

${ }^{59}$ Cf. $M A$ 8, 701b35-36.
} 
can be simply identified with its object; but in some emotions at least this certainly seems to be the case.

\subsection{Conclusion}

Through this article I have analyzed, first, the context of the presentation of emotions in de An I 1 in order to assess the methodological aim of this discussion and the sense in which emotions involve both body and soul in an inextricable way in Aristotle. Taking into account the reading of Rapp and Charles that underlines this inextricability to conclude that Aristotle would have thus avoided the problem of the causal interaction between soul (or mind) and body, I have considered what this reading has left out. Most of de An I 1 is concerned with only two causes of the emotion, matter and form, and so is Rapp's and Charles' reading. In making a reconstruction of the four causes involved in emotions, I hope I have successfully shown that the causal interaction of mind and body remains part of the Aristotelian emotions, especially when one considers the efficient cause of emotion, which is an intentional object that cannot be but the content of a mental act.

Schematically, I have suggested that emotions involve, on the one hand, simultaneous causes, which are matter, form, and the intentional object (which in some emotions can be identified with the end) of the emotion. On the other hand, there is a fourth, efficient cause of the emotion, which is the evaluative content of a representation that triggers the emotion. Each of these contributes in a different manner to the emotion, and depending on the particular circumstances can acquire more or less preeminence than the others.

The schematic and fairly preliminary analysis of the fourfold causal structure of emotions that I have offered in the second part of this article is also intended as a hermeneutical starting point for a study of particular emotions in Aristotle and beyond. The Aristotelian manifold conception of causality seems prima facie a promising stance to account for the many aspects of the complex phenomenon of emotion, including its physiological causes, its mental causes, and its intentional object. The productivity of this hermeneutical strategy, in any case, shall be put to the test in further analyses of particular emotions. This task I intend to undertake on future occasions.

\section{Bibliography}

\section{Ancient Texts}

Aristoteles, Ethica Nicomachea, ed. I. Bywater (Oxford 1894).

Aristoteles, De Generatione et Corruptione, a revised text with introduction and commentary by H. Joachim (Oxford 1926). 
Aristoteles, Parva Naturalia, A revised text with introduction and commentary by W. D. Ross (Oxford 1955).

Aristoteles, Categoriae et Liber De Interpretatione, ed. L. Minio-Paluello (Oxford 1949, repr. 1956a). Translation in Barnes.

Aristoteles, Physica, ed. W. D. Ross (Oxford 1956b).

Aristoteles, Les Parties des Animaux, ed. P. Louis (Paris 1956c).

Aristoteles, Metaphysica, ed. W. Jaeger (Oxford 1957).

Aristoteles, Topica et Sophistici Elenchi, ed. W. D. Ross (Oxford 1958).

Aristoteles, Ars Rhetorica, ed. W. D. Ross (Oxford 1959).

Aristoteles, De la Génération des Animaux, ed. P. Louis (Paris 1961).

Aristoteles, Analytica Priora et Posteriora, ed. D. W. Ross (Oxford 1964).

Aristoteles, De Motu Animalium, text with Translation, Commentary, and interpretive essays by M. C. Nussbaum (Princeton 1978).

Aristoteles, Ethica Eudemia, ed. R. Walzer, J. Mingay (Oxford 1991).

Aristoteles, De Anima, edited with Introduction and Commentary by W. D. Ross (Oxford 1961, repr. 1999).

\section{Modern Texts}

Aristotle. (1991). In J. Barnes (Ed.), Complete works (Vol. 2). Princeton: Princeton University Press.

Boeri, M. (2007). Apariencia y realidad en el pensamiento griego. Colihue.

Boeri, M. (2010). Aristóteles, Acerca del alma. Colihue.

Bonitz, H. (1961), Index Aristotelicus. Walter de Gruyter Verlag.

Caston, V. (2008). Commentary on Charles. Proceedings of the Boston Area Colloquium in Ancient Philosophy XXIV.

Charles, D. (2011). Desire in action: Aristotle's move. In M. Pakaluk \& G. Pearson (Eds.), Moral psychology and human action in Aristotle. Oxford: Oxford University Press.

Cooper, J. (1996). An Aristotelian theory of the emotions. In A. Oksenberg Rorty (Ed.), Essays on Aristotle's Rhetoric. Berkeley: University of California Press.

Dow, J. (2011). Aristotle's theory of the emotions: Emotions as pleasures and pains. In M. Pakaluk \& G. Pearson (Eds.), Moral psychology and human action in Aristotle. Oxford: Oxford University Press.

Fortenbaugh, W. (2002). Aristotle on emotion. London: Duckworth.

Frede, D. (1996). Mixed feelings in Aristotle's Rhetoric. In A. Oksenberg Rorty (Ed.), Essays on Aristotle's rhetoric. Berkeley: University of California Press.

Goldie, P. (2000). The emotions. A philosophical exploration. Oxford: Oxford University Press.

Kenny, A. (2003). Action, emotion and will. Abingdon: Routledge.

Leighton, S. (1996). Aristotle and the emotions. In A. Oksenberg Rorty (Ed.), Essays on Aristotle's rhetoric. Berkeley: University of California Press.

Moss, J. (2012). Aristotle on the apparent good. Oxford: Oxford University Press.

Nussbaum, M. (1996). Aristotle on emotions and rational persuasion. In A. Oksenberg Rorty (Ed.), Essays on Aristotle's Rhetoric. Berkeley: University of California Press.

Polansky, R. (2007). Aristotle's De anima. Cambridge: Cambridge University Press.

Rapp, C. (2006). Interaction of body and soul: What the Hellenistic philosophers saw and Aristotle avoided. In R. A. King (Ed.), Common to body and soul. Berlin: de Gruyter.

Rapp, C. (2008). Aristoteles: Bausteine für eine Theorie der Emotionen. In U. Renz \& H. Landweer (Eds.), Klassische Emotionstheorien. Von Platon bis Wittgenstein. Berlin: de Gruyter.

Rapp, C. (2013). The emotional dimension of friendship. Anuario Filosófico, 46(1).

Sherman, N. (1989). The fabric of character. Oxford: Oxford University Press. 
Solomon, R. (2003). What is an emotion? Oxford: Oxford University Press.

Striker, G. (1996). Emotions in context: Aristotle's treatment of the passions in the Rhetoric and his moral psychology. In A. Oksenberg Rorty (Ed.), Essays on Aristotle's Rhetoric. Berkeley: University of California Press.

Viano, C. (2010). Les passions comme causes dans la Rhétorique d'Aristote: mobiles de l'action et instruments de la persuasion. Journal of Ancient Philosophy, Vol. IV(1). 